\title{
Intestinal Dipeptide Absorption Is Preserved During Thermal Injury and Cytokine Treatment
}

Journal of Parenteral and Enteral Nutrition Volume 33 Number 5 September/October 2009 520-528 (C) 2009 American Society for Parenteral and Enteral Nutrition $10.1177 / 0148607109333002$ http://jpen.sagepub.com hosted at http://online.sagepub.com

\section{David R. Foster, PharmD ${ }^{1}$; Jeffrey P. Gonzales, PharmD ${ }^{2}$; Gordon L. Amidon, $\mathrm{PhD}^{3}$; and Lynda S. Welage, PharmD, FCCP}

Financial disclosure: this work was supported in part by the American College of Clinical Pharmacy Research Institute-Bayer Pharmaceuticals Critical Care Fellowship and NIH/NIGMS 5 R01 GM37188.

Background: Intestinal barrier function is impaired during thermal injury; however, the effects of thermal injury on the absorption of dietary peptides are not well characterized. The purpose of this study was to determine the impact of thermal injury on dipeptide absorption in rats and to describe the influence of inflammatory cytokines on the expression of the oligopeptide transporter PEPT1 and dipeptide permeability in cultured intestinal cells (Caco-2 cells). Methods: Sprague Dawley rats were assigned to $30 \%$ body surface area burn $(n=7)$ or sham $(n=8)$ groups. Twenty-four hours following burn/sham, the proximal jejunum was cannulated. The jejunal segment was perfused with buffer containing the dipeptide glycylsarcosine (Gly-Sar), and intestinal permeability $\left(P_{e f f}\right)$ was calculated. For in vitro experiments, Caco-2 cells were grown on permeable supports and treated with tumor necrosis factor (TNF)- $\alpha$, interleukin (IL)-6, and IL-10 (10 ng/mL) alone and in combination for 48 hours.
The effective apical-to-basolateral permeabilities $\left(P_{e f f}\right)$ of Gly-Sar were measured, and PEPT1 expression was determined using reverse transcription-polymerase chain reaction. Results: Gly-Sar $P_{\text {eff }}$ was similar in burn and sham rats $\left(6.67 \pm 2.27 \times 10^{-5}\right.$ vs 7.58 $\pm 2.20 \times 10^{-5} \mathrm{~cm} / \mathrm{s}$, respectively, $\left.P=.45\right)$. In Caco-2 cells, cytokine treatment did not alter PEPT1 expression $(P=.954)$ or the $P_{\text {eff }}$ of Gly-Sar $(P=.806)$. Conclusions: Intestinal absorption of the dipeptide Gly-Sar is preserved 24 hours following thermal injury in rats. Likewise, PEPT1 expression and peptide absorption are preserved following treatment with TNF- $\alpha$, IL-6, and IL-10 in Caco-2 monolayers. These findings imply that intestinal dipeptide absorption may be preserved during burn injury. This may lead to new strategies to optimize enteral protein delivery in burn patients. (JPEN J Parenter Enteral Nutr. 2009;33:520-528)

Keywords: PEPT1; burn; Caco-2 cells; dipeptides
$\mathrm{T}$ The intestinal epithelium is an efficient, selective barrier that facilitates the absorption of nutrients while simultaneously limiting the absorption of antigenic and noxious material. The permeation of macromolecules through the intestine is mediated via several

From the ${ }^{1}$ Department of Pharmacy Practice, Purdue University School of Pharmacy and Pharmaceutical Sciences, Indianapolis, Indiana; ${ }^{2}$ Department of Pharmacy Practice and Science, University of Maryland School of Pharmacy, Baltimore, Maryland; ${ }^{3}$ Department of Pharmaceutical Sciences, University of Michigan, College of Pharmacy, Ann Arbor, Michigan; ${ }^{4}$ Department of Clinical, Social and Administrative Sciences, University of Michigan College of Pharmacy, and Department of Pharmacy Services, University of Michigan Hospitals, Ann Arbor, Michigan.

Received for publication May 23, 2008; accepted for publication July 24, 2008.

Address correspondence to: Lynda S. Welage, PharmD, University of Michigan College of Pharmacy, 428 Church Street, Ann Arbor, MI 48109-1065; e-mail: lswelage@umich.edu. processes. In general, permeation occurs via passive or carrier-mediated transport mechanisms. Passive transport can result from the passage of molecules through the cell membrane itself (via diffusion through the membrane or pores that exist on the membrane, ie, transcellular permeation) or by passage between adjacent cells (through tight junctions, ie, paracellular permeation). In contrast, active transport processes usually involve specific transporter proteins responsible for the absorption of amino acids, oligopeptides, organic anions, organic cations, carbohydrates, and other molecules. ${ }^{1}$

Considerable evidence indicates that the integrity of the intestinal barrier is diminished as a result of burn injury and other conditions associated with profound inflammation. $^{2-7}$ In burn injury, gut mucosal weight, protein, and DNA content are all decreased, leading to a decrease in functional surface area of the small bowel. ${ }^{8-11}$ Although the precise cause of altered gut integrity is unknown, studies suggest that inflammatory cytokines (both local and systemic) and intestinal 
ischemia-reperfusion play an important role in causing intestinal dysfunction. ${ }^{12-16}$ To this end, plasma elevations in interleukin (IL)-6 are seen within hours following burn injury and exhibit a time course similar to that of alterations in intestinal integrity. ${ }^{17,18}$ Similarly, increases in IL-6 production by enterocytes and gut macrophages occur within 24 hours of thermal injury. ${ }^{19}$ Plasma IL-6 concentrations correlate with burn severity and are predictive of outcome, including mortality. ${ }^{18,20-22}$ Plasma tumor necrosis factor (TNF)- $\alpha$ concentrations are increased within 2-12 hours following burn injury, and TNF- $\alpha$ has also been associated with intestinal permeability in burn. ${ }^{23}$ Clinically, these phenomena may result in bacterial translocation from the gut, subsequently leading to multiple organ dysfunction. ${ }^{3,6}$ IL-10 is an antiinflammatory cytokine that is also produced following burn injury; plasma IL-10 concentrations may also be associated with outcome in burn (higher concentrations on admission may be associated with increased mortality), and IL-10 may attenuate inflammation related changes in intestinal cells. ${ }^{24-26}$

Although many studies have described alterations in intestinal barrier function via increased paracellular permeability following burn injury, very few have focused on potential alterations in nutrient absorption, particularly those that are mediated by active processes. The absorption of certain amino acids (proline, leucine, glutamic acid, and arginine) actively absorbed via a number of transport proteins in the small intestine is impaired in experimental sepsis models, although it is unknown whether similar changes occur in burn. ${ }^{27-31}$ Of note, others have observed a decrease in carrier-mediated glutamine transport in a rat burn model. ${ }^{32}$

The active intestinal absorption of dipeptides and tripeptides is mediated by the oligopeptide transporter PEPT1 (SLC15A1, h-PEPT1 in humans, r-PEPT1 in rats), a proton-coupled transporter present in the brushborder membrane of the small intestine. ${ }^{33,34}$ PEPT1 is generally considered to be a low-affinity, high-capacity transporter that has affinity for a diverse array of substrates, although specific structure-activity relationships have not been established. ${ }^{34}$ PEPT1 is also of considerable pharmacological importance. In addition to transporting oligopeptides, this transporter is also responsible for the intestinal absorption of a number of pharmaceuticals, including $\beta$-lactam antibiotics, renin inhibitors, antivirals, antineoplastics, L-valyl ester prodrugs (eg, valacyclovir, valgancyclovir), and others. ${ }^{33,34}$

The objectives of the current study were twofold. First, to evaluate the impact of thermal injury on intestinal dipeptide absorption, we studied the absorption of the model dipeptide glycylsarcosine (Gly-Sar) in a rat model of thermal injury. Second, because of the substantial contribution of inflammatory cytokines to burn-induced intestinal alterations, we sought to determine the effects of the inflammatory cytokines TNF- $\alpha$ and IL-6 and the anti-inflammatory cytokine IL-10 on the expression of PEPT1 and the permeation of Gly-Sar in cultured human intestinal cells (Caco-2 cells).

\section{Materials and Methods}

\section{Materials}

$\left[{ }^{3} \mathrm{H}\right]$ Gly-Sar was obtained from Moravek Biochemicals (Brea, CA), $\left[{ }^{14} \mathrm{C}\right]$ polyethylene glycol (PEG) 4000 from Amersham (Arlington Heights, IL), and $\left[{ }^{3} \mathrm{H}\right]$ mannitol from Sigma Chemical (St. Louis, MO). Dulbecco's modified Eagle's medium, nonessential amino acids, sodium pyruvate, Trizol ${ }^{\circledR}$, and $4 \%-20 \%$ tris/borate/EDTA (TBE) gels were purchased from Invitrogen Corporation (Carlsbad, CA). Heat-inactivated fetal-bovine serum, penicillinstreptomycin, HEPES buffer (4-[2-hydroxyethyl]-1-piperazineethanesulfonic acid), trypsin-versine (EDTA), and Scinti-Safe ${ }^{\circledR}$ scintillation cocktail were purchased from Fisher Scientific (Pittsburgh, PA). Recombinant human TNF- $\alpha$, IL-6, and IL-10 were purchased from Peprotech (Rocky Hill, NJ). Cell culture dishes were manufactured by Corning Costar (Corning, NY). Enzymes and reagents used in reverse transcription-polymerase chain reactions (Access RT-PCR kit) were obtained from Promega Corporation (Madison, WI). All other chemicals were obtained from Sigma Chemical (St. Louis, MO) unless otherwise noted.

\section{Dipeptide Permeability Following Thermal Injury}

Animals. Male Sprague Dawley rats (250-300 g; Charles River Laboratories, Wilmington, MA) were housed in controlled conditions (12-hour light cycle) and acclimated for at least 1 week prior to experiments. All animal procedures were approved by the University Committee on Use and Care of Animals at the University of Michigan. The study conformed to the Guide for the Care and Use of Laboratory Animals published by the National Institutes of Health (revised in 1996).

Thermal injury model. Animals were assigned to receive either burn $(n=7)$ or sham $(n=8)$ treatment. Sham rats received treatment identical to burn rats with the exception of the actual burn injury. Rats in the burn group received a 30\% total body surface area (TBSA) full-thickness scald burn. ${ }^{35}$ Briefly, following a 12-hour fast (water available ad libitum), animals were anesthetized with an intraperitoneal injection of sodium pentobarbital (40 mg/ $\mathrm{kg}$ ). The hair on the dorsal aspect of the rats was shaved, and animals were placed in a custom-made insulated mold, exposing a portion of their dorsum accounting for 
$30 \%$ of their TBSA. Rats assigned to burn treatment were immersed in $99^{\circ} \mathrm{C}$ water for 13 seconds, whereas those assigned to sham treatment were immersed in room temperature water for 13 seconds. Following burn injury, rats received fluid resuscitation with intraperitoneal lactated Ringer's solution using a modified Parkland formula ( $3 \mathrm{~mL} / \mathrm{kg}$ per percentage of TBSA burned, two-thirds of which was administered immediately following burn injury and one-third of which was administered 8 hours after injury), and were administered morphine $(1.5 \mathrm{mg} / \mathrm{kg}$ subcutaneously). Following recovery from anesthesia, animals were returned to their cages and allowed access to food and water ad libitum.

Single pass in situ jejunal perfusion. Twelve hours after burn or sham treatment, animals were again fasted, with water available ad libitum. Subsequently, 24 hours after burn/ sham treatment, rats were anesthetized with intraperitoneal sodium pentobarbital $(40 \mathrm{mg} / \mathrm{kg})$ and intramuscular ketamine $(20 \mathrm{mg} / \mathrm{kg})$. A laparotomy was performed, and a segment of the proximal jejunum was cannulated at 2 sites with plastic tubing, creating a $10-\mathrm{cm}$ closed segment. The segment was kept moist by placing saline-soaked gauze and Parafilm M (Pechiney Plastic Packaging, Chicago, IL) over the site. Isotonic buffer solution was perfused through the segment at a rate of $0.2 \mathrm{~mL} / \mathrm{min}$ using a syringe pump (KD Scientific, New Hope, PA). The perfusion solution consisted of $135 \mathrm{mM} \mathrm{NaCl}, 5 \mathrm{mM} \mathrm{KCl}, 5 \mathrm{mM} \mathrm{NaOH}, 5 \mathrm{mM}$ MES (2-[N-morpholino]ethanesulfonic) free acid hydrate, and $0.5 \mathrm{mM}\left[{ }^{3} \mathrm{H}\right]$ Gly-Sar. PEG4000 containing a trace amount of $\left[{ }^{14} \mathrm{C}\right]$ PEG4000 was added to the perfusion solution as a poorly absorbed marker to account for fluid loss or membrane leakage. The $\mathrm{pH}$ of the perfusion solution was 6.5 and the osmolarity was adjusted to $290 \pm 5 \mathrm{mOsm} / \mathrm{L}$. Outlet perfusate was collected at 10-minute intervals. Following the 2-hour, closed-loop, in situ perfusion, rats were sacrificed. $\left[{ }^{3} \mathrm{H}\right]$ Gly-Sar and $\left[{ }^{14} \mathrm{C}\right]$ PEG4000 concentrations of each 10-minute outlet perfusate samples were determined using a Beckman LS 6000SC scintillation counter (Beckman Instruments, Fullerton, CA).

Data analysis. Absorption was characterized by calculating the effective permeability of Gly-Sar, as previously described. ${ }^{36-39}$ Briefly, effective permeability was calculated using the following equation:

$$
P_{e f f}=\frac{\left[Q \times\left(\frac{1-C_{\text {out }}}{C_{\text {in }}}\right)\right]}{2 \pi R L}
$$

where $P_{\text {eff }}$ is the effective permeability $(\mathrm{cm} / \mathrm{s}), Q$ is the flow rate of the perfusion solution through the segment $(0.2 \mathrm{~mL} / \mathrm{min}), C_{\text {in }}$ and $C_{\text {out }}$ are the inlet and outlet Gly-Sar concentrations, $R$ is the intestinal radius $(\mathrm{cm}$; approximated to be $0.18 \mathrm{~cm}$ for all animals), and $\mathrm{L}$ is the length of the perfused intestinal segment. ${ }^{39}$ Inlet and outlet concentrations were corrected for net absorption or secretion of water by multiplying $C_{\text {out }} / C_{\text {in }}$ by [PEG4000 $]_{\text {out }} /$ $[\text { PEG4000 }]_{\text {in }}$. Permeability values reported are mean values at steady state after excluding outliers. Specifically, if the water transport $(\% / \mathrm{cm})$ in the segment was $> \pm 1 \%$ for $\geq 50 \%$ of the steady-state time points, mucosal integrity was considered compromised and permeability data from the animal were excluded from analysis.

\section{Dipeptide Absorption Following Cytokine Treatment}

Cell culture. Caco-2 cells (passage 40-50) were grown at $37^{\circ} \mathrm{C}$ in $5 \% \mathrm{CO}_{2}$ in $100-\mathrm{mm}$ culture dishes, in Dulbecco's modified Eagle's medium, supplemented with $10 \%$ fetal bovine serum, $1 \%$ nonessential amino acids, $1 \%$ sodium pyruvate, $10 \mathrm{mM}$ HEPES, 100 units/mL penicillin, and $0.1 \mathrm{mg} / \mathrm{L}$ streptomycin. Growth medium was replaced thrice weekly. After achieving confluence in $100-\mathrm{mm}$ culture dishes (5-7 days), cell monolayers were disrupted using trypsin-versine and seeded onto permeable collagen-coated polyester supports ( $3 \mu \mathrm{m}$ pore diameter) (Transwell ${ }^{\circledR}$, Corning Costar) at a density of 100,000 cells $/ \mathrm{mL}$. For permeability experiments, $6.5-\mathrm{mm}$ diameter supports were used, whereas 24-mm supports were used to obtain RNA for reverse transcription-polymerase chain reaction (RT-PCR). Cells were grown on these supports in the above conditions for a total of 21 days prior to cytokine treatment (see below).

Cytokine treatment. All experiments were conducted in triplicate. Prior to cytokine treatment, transepithelial electrical resistance (TEER) was measured using an epithelial ohmmeter (EVOM, World Precision Instruments, Sarasota, FL); only confluent monolayers (defined as cell inserts with TEER $\geq 200 \Omega \cdot \mathrm{cm}^{2}$, corrected for membrane resistance) were used in experiments. The following 5 experimental groups of monolayers were treated with cytokines $(10 \mathrm{ng} / \mathrm{mL}$, in media as described above, added to the basolateral compartments of the cell chambers) for 48 hours: TNF- $\alpha$, IL-6, IL-10, TNF- $\alpha$ plus IL-6, and TNF- $\alpha$ plus IL-6 plus IL-10. Control cultures were treated with normal media.

Absorption. Following cytokine or control treatment, TEER was again measured and the effective permeabilities of the cell monolayers to Gly-Sar and mannitol were determined. Permeability experiments were carried out using an apical transport buffer $\left(\mathrm{NaCl} 150 \mathrm{mM}, \mathrm{KCl} 3 \mathrm{mM}, \mathrm{NaH}_{2} \mathrm{PO}_{4} 1\right.$ $\mathrm{mM}, \mathrm{CaCl}_{2} 1 \mathrm{mM}, \mathrm{MgCl}_{2} 6 \mathrm{H}_{2} \mathrm{O} 1 \mathrm{mM}$, MES [2-(N-morpholino)ethanesulfonic acid] $5 \mathrm{mM}$, D-glucose $5 \mathrm{mM}, \mathrm{pH}$ 6.0) and a basolateral transport buffer $(\mathrm{NaCl} 150 \mathrm{mM}$, 
$\mathrm{KCl} 3 \mathrm{mM}, \mathrm{NaH}_{2} \mathrm{PO}_{4} 1 \mathrm{mM}, \mathrm{CaCl}_{2} 1 \mathrm{mM}, \mathrm{MgCl}_{2} 6 \mathrm{H}_{2} \mathrm{O} 1$ $\mathrm{mM}$, HEPES $5 \mathrm{mM}$, D-glucose $5 \mathrm{mM}, \mathrm{pH}$ 7.4). $\left[{ }^{3} \mathrm{H}\right]$ GlySar $(10 \mathrm{mM})$ or $\left[{ }^{3} \mathrm{H}\right]$ mannitol $(0.22 \mathrm{mM})$ was added to the apical chambers, and basolateral concentrations of markers were measured at $0,15,30,45,60$, and 120 minutes, under sink conditions. $\left[{ }^{3} \mathrm{H}\right]$ Gly-Sar and $\left[{ }^{3} \mathrm{H}\right]$ mannitol concentrations were measured using a Beckman LS 6000SC scintillation counter (Beckman Instruments, Fullerton, CA).

Data analysis. Permeation of Gly-Sar and mannitol was characterized using their effective permeability coefficients $\left(\mathrm{P}_{\text {eff }}\right)$. Permeability coefficients were calculated using the following equation:

$$
P_{e f f}=\frac{(d Q / d t)}{\left(A * C_{a}\right)}
$$

where $\mathrm{dQ} / \mathrm{dt}$ is the rate of accumulation of substrate in the basolateral chamber, $\mathrm{A}$ is the surface area of the membrane, and $\mathrm{C}_{\mathrm{a}}$ is the initial concentration of substrate in the apical chamber, as described previously. ${ }^{40}$

PEPT1 expression. The effects of cytokine treatment on PEPT1 messenger RNA (mRNA) expression were determined using semiquantitative RT-PCR as described previously. ${ }^{41}$ Caco-2 cells were removed from $24-\mathrm{mm}$ permeable supports, and total RNA was isolated using a commercially available RNA isolation kit (TRIzol $\AA$, Invitrogen Corporation, Carlsbad, CA) per the manufacturer's instructions. RNA was converted to complementary DNA (cDNA) using a reverse-transcription system (Access RT-PCR ${ }^{\circledR}$, Promega, Madison, WI). Briefly, 50- $\mu \mathrm{L}$ reaction mixtures, consisting of 5 units avian myeloblastosis virus (AMV) reverse transcriptase, 5 units Tfl DNA polymerase, $10 \mu \mathrm{L} 5 \times \mathrm{AMV} / \mathrm{Tfl}$ reaction buffer, $1 \mathrm{mM} \mathrm{MgSO}$, $0.2 \mathrm{mM}$ dNTPs (deoxynucleosides), $1 \mu \mathrm{M}$ each upstream and downstream primer (see below), $1 \mu \mathrm{g}$ total RNA, and $33 \mu \mathrm{L}$ nuclease-free water, were prepared. The composition of the primer pair was as follows: sense 5'-GCAGTCACCTCAGTAAGCT-3' and antisense 5'-GCTGCTGATGTTTGCATA-3'. The PCR reaction was carried out using a GeneAmp 2400 thermalcycler (Applied Biosystems, Foster City, CA). Following a single cycle of reverse transcription and reverse transcriptase deactivation/RNAcDNA primer denaturation $\left(48^{\circ} \mathrm{C}\right.$ for 45 minutes, then $94^{\circ} \mathrm{C}$ for 2 minutes), samples underwent 25 cycles of denaturation, annealing, and extension $\left(94^{\circ} \mathrm{C}\right.$ for $30 \mathrm{sec}-$ onds, $54^{\circ} \mathrm{C}$ for 1 minute, and $68^{\circ} \mathrm{C}$ for 2 minutes) and a single final extension $\left(68^{\circ} \mathrm{C}\right.$ for 1 minute). cDNA samples were held at $4^{\circ} \mathrm{C}$ until gel electrophoresis. The PCR products were separated on 4\%-20\% TBE gels. Gels were stained using SYBR-Green, and densitometric analyses

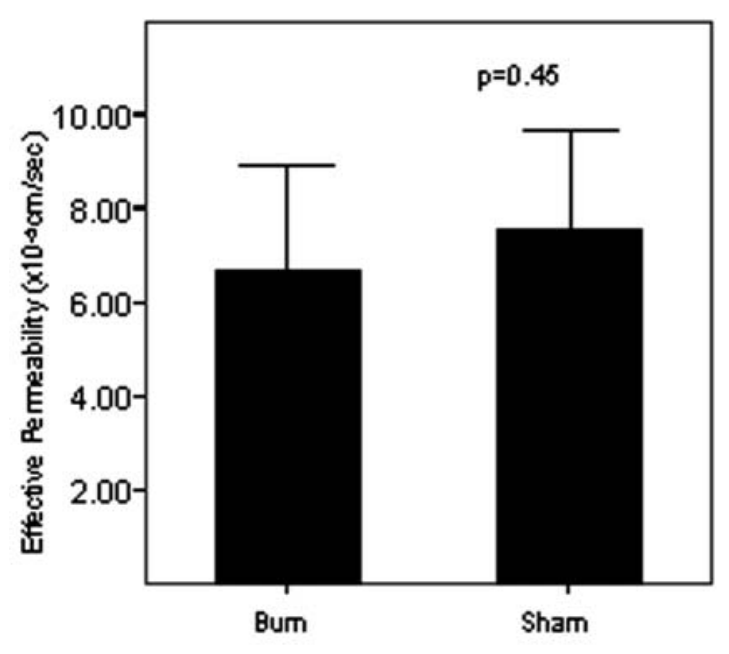

Figure 1. Effective permeability $\left(P_{\text {eff }}\right)$ of glycylsarcosine (GlySar) in burn $(\mathrm{n}=7)$ and sham $(\mathrm{n}=8)$ rats following $30 \%$ total body surface area full-thickness scald injury. $P=.45$ (Student's $t$ test).

were performed using a Kodak photo documentation system (Kodak, New Haven, CT).

Statistical analyses. All data are presented as mean \pm standard deviation unless otherwise stated. A 2-tailed Student's $t$ test was used to compare $P_{\text {eff }}$ between the burn and sham groups. Analysis of variance (ANOVA) models with post hoc analyses using Tukey's test were used in the analyses of Gly-Sar $P_{\text {eff }}$ and PEPT1 expression in Caco-2 experiments. All tests were conducted using SPSS 11.0 (SPSS Inc, Chicago, IL), and for all tests, $P \leq .05$ was considered to be significant.

\section{Results}

\section{Dipeptide Absorption Following Thermal Injury}

Data from 2 rats in the burn group were excluded from analysis for not meeting the a priori defined criteria for water transport as described in the methods section. Thus, data from 7 rats in the burn group and 8 rats in the sham group were included in the final analysis. Gly-Sar permeability was well preserved following thermal injury. Specifically, Gly-Sar $P_{\text {eff }}$ was $6.67 \pm 2.27 \times 10^{-5}$ vs $7.58 \pm$ $2.20 \times 10^{-5} \mathrm{~cm} / \mathrm{s}$, in burn and sham rats, respectively $(P=.45$, Figure 1). Fraction of Gly-Sar dose absorbed approached $100 \%$ in both groups $(95.0 \%$ vs $96.8 \%$ in burn and sham animals, respectively, $P=.38$ ). 


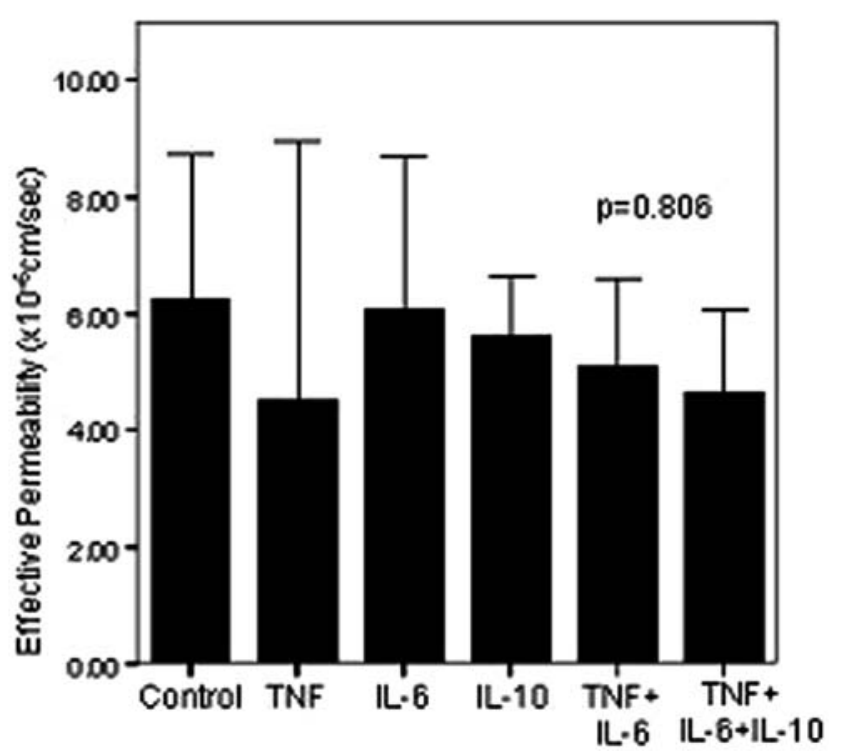

Figure 2. Effective permeability $\left(P_{\text {eff }}\right)$ of glycylsarcosine (GlySar) in Caco-2 monolayers treated with control media, tumor necrosis factor (TNF)- $\alpha$, interleukin (IL)-6, IL-10, TNF- $\alpha$ plus IL-6, and TNF- $\alpha$ plus IL-6 plus IL-10 (concentration of all cytokines is $10 \mathrm{ng} / \mathrm{mL}$ ). Bars represent means, lines represent standard deviations. $P=.806$ (ANOVA).

\section{Dipeptide Absorption Following Cytokine Treatment}

Gly-Sar and mannitol permeability. The permeability of Caco-2 monolayers to Gly-Sar was unaffected by treatment with IL-6, TNF- $\alpha$, IL-10, or the combinations of TNF- $\alpha$ plus IL-6 and TNF- $\alpha$ plus IL-6 plus IL-10; mean effective permeabilities ranged from $4.65 \times 10^{-6} \mathrm{~cm} / \mathrm{s}$ (with the combination of TNF- $\alpha$, IL-6, and IL-10) to $6.09 \times$ $10^{-6} \mathrm{~cm} / \mathrm{s}$ (with IL-6 treatment) $(P=.806$, Figure 2$)$. Similarly, the permeation of mannitol, a passively absorbed marker, was also unaltered by cytokine treatment $(P=$ .985 , Figure 3). Mean mannitol effective permeabilities ranged from $0.917 \times 10^{-5} \mathrm{~cm} / \mathrm{s}$ in IL-10-treated groups to $1.06 \times 10^{-5} \mathrm{~cm} / \mathrm{s}$ in control groups (Figure 3).

TEER. TEER was measured in this study prior to and following incubation with cytokines or control media. Cytokine treatment resulted in marked changes in the overall barrier integrity $(P<.001$, Figure 4$)$. Post hoc analyses confirmed that, compared with controls, treatment with IL-6 alone, and in combination with both TNF- $\alpha$ and TNF- $\alpha$ plus IL-10, significantly reduced TEER $(P<.05$ for each comparison). In contrast, treatment with the anti-inflammatory cytokine IL-10 resulted in improved monolayer integrity $(P<.01$, compared with all other groups). IL-10 (when combined with IL-6 and TNF- $\alpha$ ) partially attenuated the effects of IL-6, as the

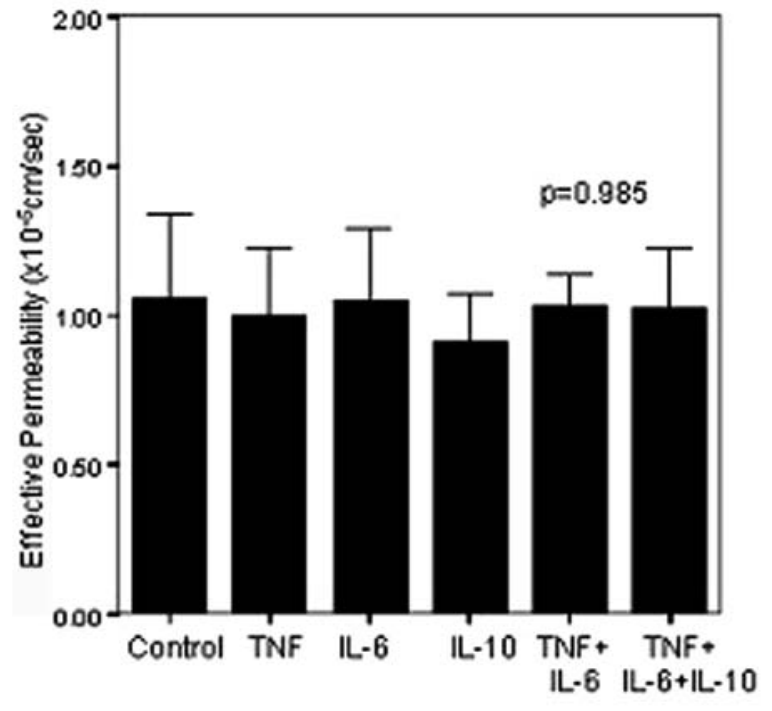

Figure 3. Effective permeability $\left(P_{\text {eff }}\right)$ of mannitol in Caco-2 monolayers treated with control media, tumor necrosis factor (TNF)- $\alpha$, interleukin (IL)-6, IL-10, TNF- $\alpha$ plus IL-6, and TNF- $\alpha$ plus IL-6 plus IL-10 (concentration of all cytokines is 10 $\mathrm{ng} / \mathrm{mL}$ ). Bars represent means, lines represent standard deviations. $P=.985$ (ANOVA).

reduction in TEER was significantly less than that caused by IL-6 alone $(P=.004)$. Complete results of the post hoc analysis are shown in Table 1.

PEPT1 expression. Semiquantitative RT-PCR was used to determine the effects TNF- $\alpha$, IL-6, and IL-10 on PEPT1 mRNA expression. PEPT1 expression was preserved following treatment with each of the cytokines and cytokine combinations tested $(P=.943$, Figure 5).

\section{Discussion}

Intestinal barrier function is impaired in burn injury and a number of inflammatory conditions. ${ }^{3,13,42-44}$ Several studies offer compelling evidence for the role of inflammatory cytokines in the pathogenesis of intestinal hyperpermeability related to burn injury and other critical illness. ${ }^{17,19,23,45-47}$ The primary focus of the majority of these studies has been the paracellular permeation of microorganisms and inflammatory stimuli. In contrast, few studies have evaluated potential changes in the intestinal absorption of nutrients, specifically those dependent on facilitated transport mechanisms. The purpose of this study was to evaluate the effects of the profound inflammatory response induced by burn injury on peptide absorption via the oligopeptide transporter PEPT1. Our results indicate that PEPT1 is, in fact, a robust transport 
Table 1. Results of the Post Hoc Analysis (Tukey's Test) of Changes in Transepithelial Resistance From Baseline

\begin{tabular}{lcccccc}
\hline Treatment & Control & TNF- $\alpha$ & IL-6 & IL-10 & TNF- $\alpha+$ IL-6 & TNF- $\alpha+$ IL-6 + IL-10 \\
\hline Control & - & NS & S & S & S & S \\
TNF- $\alpha$ & NS & - & S & S & S & S \\
IL-6 & S & S & - & S & NS & S \\
IL-10 & S & S & S & - & - & NS \\
TNF- $\alpha+$ IL-6 & S & S & NS & S & NS & - \\
TNF- $\alpha+$ IL-6 + IL-10 & S & S & S & S & .
\end{tabular}

TNF, tumor necrosis factor; IL, interleukin; S, significant difference $(P \leq .05)$; NS, nonsignificant difference $(P>.05)$. Caco-2 monolayers were treated with treated with control media, TNF- $\alpha$, IL-6, IL-10, TNF- $\alpha$ plus IL-6, and TNF- $\alpha$ plus IL-6 plus IL-10 (concentration of all cytokines is $10 \mathrm{ng} / \mathrm{mL}$ ). Results are pooled results from multiple permeability experiments.

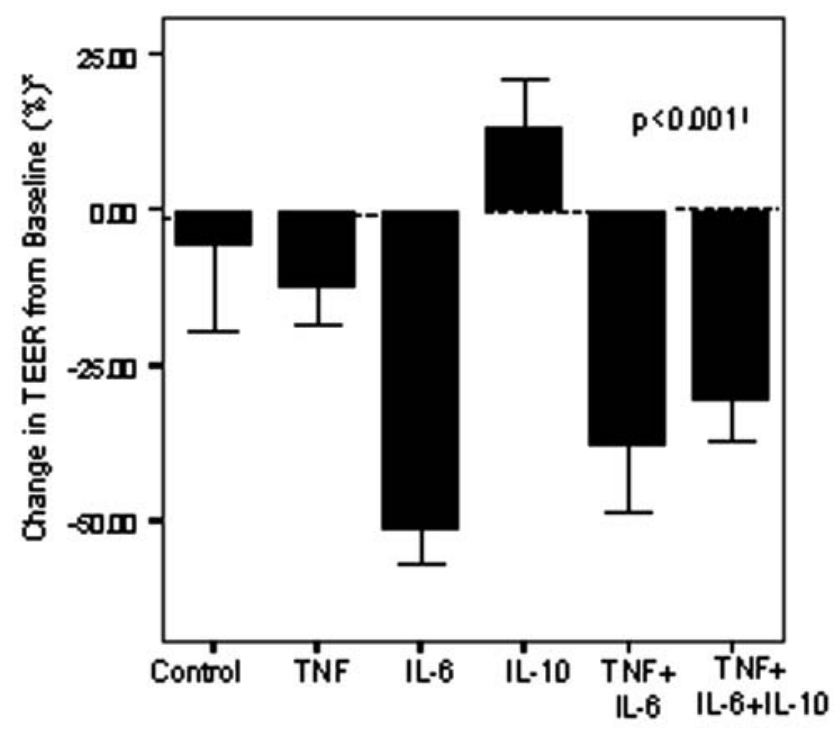

Figure 4. Change in transepithelial electrical resistance (TEER) from baseline of Caco-2 monolayers treated with treated with control media, tumor necrosis factor (TNF)- $\alpha$, interleukin (IL)-6, IL-10, TNF- $\alpha$ plus IL-6, and TNF- $\alpha$ plus IL-6 plus IL-10 (concentration of all cytokines is $10 \mathrm{ng} / \mathrm{mL}$ ). Results are pooled results from multiple permeability experiments. Bars represent means; lines represent standard deviations. $P<.001$ (ANOVA); results of post hoc analysis are shown in Table 1.

system. Specifically, the jejunal absorption of Gly-Sar, the marker dipeptide used in the study, is unaltered following a 30\% TBSA full-thickness burn injury in rats. Because many of the intestinal changes during burn injury are mediated by inflammatory cytokines, we also studied the effects of inflammatory cytokines on PEPT1 function and expression in cultured intestinal cells (Caco-2 cells). Consistent with the results of our animal experiments, Gly-Sar permeability and PEPT1 mRNA expression were preserved in Caco-2 monolayers treated with IL-6 and TNF- $\alpha$ separately, in addition to the combinations of IL-6 and TNF- $\alpha$ and that of IL-6, TNF- $\alpha$, and IL-10. Although

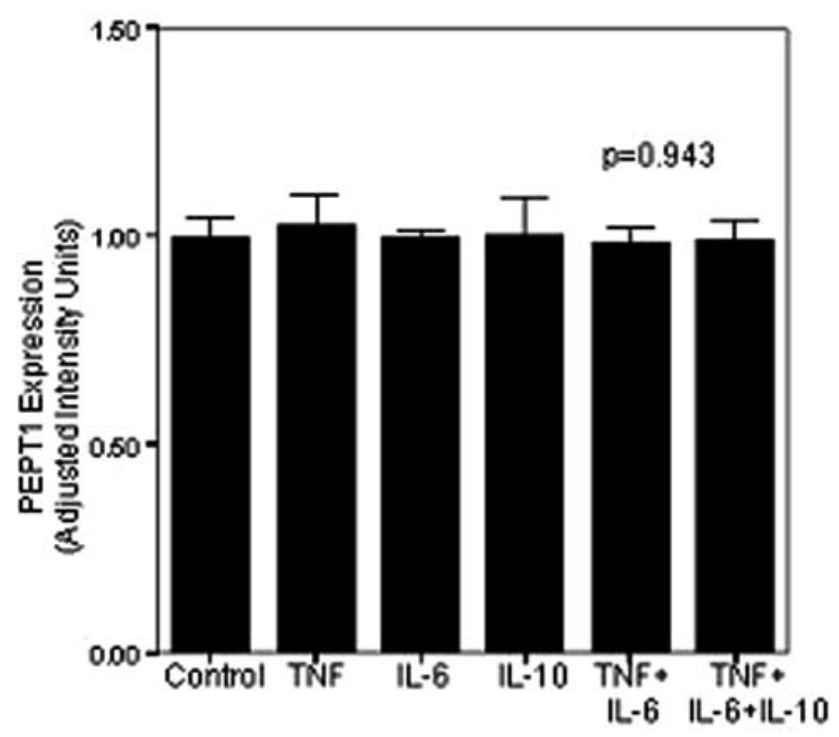

Figure 5. PEPT1 RNA expression following cytokine treatment. RNA samples were analyzed in triplicate using RT-PCR. Results of densitometric analyses are shown: bars represent means; lines represent standard deviations. $P=.943$ (ANOVA). TNF, tumor necrosis factor; IL, interleukin.

we did not confirm our mRNA results by quantifying PEPT1 protein expression, our mRNA expression results are supported by our functional studies (ie, Gly-Sar permeability) in both animal and in vitro experiments.

In conjunction with the assessment of Gly-Sar permeability, we also determined the influence of IL-6, TNF- $\alpha$, and IL-10 on the effective permeability of mannitol and the overall integrity of the Caco-2 monolayers (as indicated by the electrical resistance posed by the membrane [TEER]). The former allowed us to assess changes in the absorption of a passively absorbed marker. Mannitol permeability in the Caco-2 monolayers was 
unchanged following cytokine treatment. Of note, this appears to be in conflict with some of the existing literature evaluating the effects of inflammatory cytokines on the permeation of passively absorbed macromolecules. ${ }^{12,14,46}$ This apparent discordance can be explained by 2 important considerations. First, in our study, experiments were 2 hours in duration, which is much shorter than the duration of many of the other studies in which permeability was assessed over a period of up to 72 hours. Second, in some of the existing studies, model epithelia were incubated with cytokines for a longer duration than the 48-hour incubation time used in the current study. Cytokine treatment resulted in marked changes in the electrical resistance posed by the Caco- 2 monolayers. In general, IL-6 resulted in a generalized reduction in monolayer integrity (whether alone or in combination). Although a mechanistic explanation for this would be speculative, this is not unexpected, because Caco-2 cells express IL-6 receptors, and IL-6 induces a broad array of effects in Caco-2 cells, including nuclear factor- $\kappa \mathrm{B}$ activation and alterations in monolayer integrity. ${ }^{48-50}$ In contrast, the antiinflammatory cytokine IL-10 appeared to have a protective or trophic effect on the Caco-2 monolayers. Over the incubation period, TEER increased from baseline in IL-10treated monolayers, whereas TEER decreased in all other groups (including marginal decreases in control and TNF$\alpha$-treated groups). Moreover, the combination of IL-10 with TNF- $\alpha$ and IL- 6 resulted in significant attenuation of the effects of IL-6 compared with treatment with IL-6 alone, although the attenuation of barrier dysfunction was not significant when the combination of all cytokines was compared with the combination of TNF- $\alpha$ and IL-6. IL-10 was assessed because of its clinical importance in burn and to determine whether IL-10 attenuates the effect of the inflammatory cytokines; similar phenomena have been demonstrated in model epithelia by other investigators. ${ }^{26}$

Our results may be subject to several criticisms. The rat thermal injury model used may not be perfectly representative of burn injury in humans. For example, to minimize animal distress, rats were anesthetized prior to burn injury; this may result in a diminished acute phase response compared with that observed clinically. However, in previous studies with this model, we have demonstrated dramatic changes in jejunal histology and alterations in intestinal $p$-glycoprotein expression, so we are relatively confident that the mechanism of injury is sufficient to affect absorptive processes influenced by inflammation and appropriate to study alterations in active transport processes. ${ }^{51}$ Controversy exists regarding the ideal choice of probe to study peptide absorption. Gly-Sar was chosen as the model substrate for dipeptide transporters in the current study for several reasons: it is hydrolysis resistant, numerous mammalian cell culture experiments indicate that it is transported by PEPT1, and it has been widely used as a prototypical PEPT1 substrate. ${ }^{1}$ It is possible, however, that Gly-Sar is a substrate for other peptide transporters in addition to PEPT1. Additionally, computergenerated conformational analyses of Gly-Sar structure and bacterial peptide transporter assays suggest that GlySar may not be an ideal substrate for some types of bacterial peptide transporters (although Gly-Sar is transported by the bacterial transporter thought to most closely resemble PEPT1). ${ }^{52}$ Despite these theoretical limitations, Gly-Sar is a well-established PEPT1 substrate and remains the most widely used probe substrate. In our rat burn model, we used PEG4000 to account for fluid loss or membrane leakage. Although it is possible that some passive absorption of PEG4000 occurred, this is likely to be insignificant compared with Gly-Sar absorption. The concentrations of cytokines used in the in vitro portions of the study (10 ng/mL for all cytokines) were derived from previously published investigations that have used model epithelia to investigate intestinal permeability and transporter protein expression. ${ }^{46,53-56}$ It is possible that these concentrations do not reflect physiologic cytokine concentrations at the enterocyte level. Unfortunately, the concentrations of these cytokines present in and around enterocytes in vivo are unknown. Moreover, these concentrations are inherently difficult to estimate, because they may be influenced by cytokine concentrations circulating systemically as well as cytokines produced locally by enterocytes and intraepithelial lymphocytes. ${ }^{56-58}$ Use of a physiologically relevant model of disease, in conjunction with evaluation using key mediators of inflammation in vitro, gives credence to our results.

Our results suggest that PEPT1 is a robust transport protein in burn injury and potentially in other states of acute inflammation that are characterized by high levels of inflammatory cytokines. Similarly, other investigations have described preservation of PEPT1 expression and/or function in a variety of conditions. For example, the cytokine interferon- $\gamma$ increases the expression of PEPT1 and the permeability of Gly-Sar in Caco-2 cells. ${ }^{59}$ Tanaka and colleagues demonstrated that during 5 -fluorouracilinduced intestinal injury in rats, the amount of PEPT1 is unaltered and Gly-Sar uptake is unchanged. ${ }^{60}$ Others have demonstrated an increase in PEPTlexpression in response to starvation. ${ }^{61,62}$ These studies, taken in the context of our current results, suggest that PEPT1mediated oligopeptide transport is well preserved in conditions of stress.

Our results have several implications in the context of burn injury. Early enteral nutrition is a hallmark of burn care, so preservation of oligopeptide absorption during burn injury and critical illness may have implications with regard to enteral protein delivery, especially given the apparent decrease in amino acid absorption that occurs and the high protein requirements

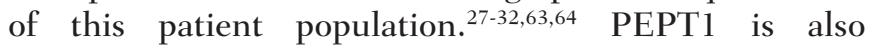
responsible for the absorption of a number of drugs, 
including $\beta$-lactam antibiotics, renin inhibitors, antivirals, antineoplastics, and others. ${ }^{40,65-66}$ Preservation of this transport system following burn injury and during cytokine-induced challenge suggests that the oral absorption of these agents may also be preserved in burn injury and other states of inflammation. Moreover, the resistance of PEPT1 to a variety of insults supports the use of this transport system in the design of future nutrition strategies. Finally, PEPT1 may actually play a role in perpetuating some inflammatory conditions via facilitating the intestinal absorption of bacterial-derived peptides, an effect that may be attenuated in vitro with PEPT1 substrates. ${ }^{67}$

\section{Conclusions}

Intestinal peptide absorption is preserved following burn injury in rats, an effect that was confirmed in Caco-2 monolayers treated with TNF- $\alpha$, IL-6, and IL-10. These findings imply that intestinal absorption of peptides/peptidomimetic drugs is preserved in burn injury. Future efforts should be targeted at exploring the in vivo significance of these findings, with the goal of optimizing enteral nutrition in burn patients.

\section{References}

1. Oh D-M, Han HK, Amidon GL. Drug transport and targeting. In: Amidon GL, Sadee W, eds. Membrane Transporters as Drug Targets. New York, NY; Kluwer Academic/Plenum; 1999:59-88.

2. Othman M, Aguero R, Lin HC. Alterations in intestinal microbial flora and human disease. Curr Opin Gastroenterol. 2008;24: 11-16.

3. Deitch EA. Intestinal permeability is increased in burn patients shortly after injury. Surgery. 1990;107:411-416.

4. Kiliaan AJ, Saunders PR, Bijlsma PB, et al. Stress stimulates transepithelial macromolecular uptake in rat jejunum. Am J Physiol. 1998;275:1037-1044.

5. Soderholm JD, Perdue MH. Stress and gastrointestinal tract, II: stress and intestinal barrier function. Am J Physiol Gastrointest Liver Physiol. 2001;280:G7-G13.

6. Deitch EA. Multiple organ failure: pathophysiology and potential future therapy. Ann Surg. 1992;216:117-134.

7. Xu DZ, Lu Q, Kubicka R, Deitch EA. The effect of hypoxia/reoxygenation on the cellular function of intestinal epithelial cells. $J$ Trauma. 1999;46:280-285.

8. Ezzell RM, Carter EA, Yarmush ML, Tompkins RG. Thermal injury-induced changes in the rat intestine brush border cytoskeleton. Surgery. 1993;114:591-597.

9. Haglund U. Systemic mediators released from the gut in critical illness. Crit Care Med. 1993;21:15-18.

10. Lefer AM, Ma XL. Cytokines and growth factors in endothelial dysfunction. Crit Care Med. 1993;21:9-14.

11. Carter EA, Udall JN, Kirkham SE, Walker WA. Thermal injury and gastrointestinal function, I: small intestinal nutrient absorption and DNA synthesis. J Burn Care Rehabil. 1986;7:469-474.

12. Parikh AA, Salzman AL, Fischer JE, Szabo C, Hasselgren PO. Interleukin-1 beta and interferon-gamma regulate interleukin-6 production in cultured human intestinal epithelial cells. Shock. 1997;8:249-255.

13. McKay DM, Baird AW. Cytokine regulation of epithelial permeability and ion transport. Gut. 1999;44:283-289.

14. Madara JL, Stafford J. Interferon-gamma directly affects barrier function of cultured intestinal epithelial monolayers. J Clin Invest. 1989;83:724-727.

15. Chavez AM, Morin MJ, Unno N, Fink MP, Hodin RA. Acquired interferon $\gamma$ responsiveness during Caco-2 cell differentiation: effects on iNOS gene expression. Gut. 1999;44:659-665.

16. Ma W, Lehner PJ, Cresswell P, Pober JS, Johnson DR. Interferongamma rapidly increases peptide transporter (TAP) subunit expression and peptide transport capacity in endothelial cells. J Biol Chem. 1997;272:16585-16590.

17. Gosain A, Gamelli RL. Role of the gastrointestinal tract in burn sepsis. J Burn Care Rehabil. 2005;26:85-91.

18. Carsin H, Assicot M, Feger F, et al. Evolution and significance of circulating procalcitonin levels compared with IL-6, TNF- $\alpha$ and endotoxin levels early after thermal injury. Burns. 1997;23: 218-224.

19. Ogle CK, Mao JX, Wu JZ, Ogle JD, Alexander JW. The 1994 Lindberg Award. The production of tumor necrosis factor, interleukin-1, interleukin-6, and prostaglandin E2 by isolated enterocytes and gut macrophages: effect of lipopolysaccharide and thermal injury. J Burn Care Rehabil. 1994;15:470-477.

20. Vanni HE, Gordon BR, Levine DM, et al. Cholesterol and interleukin-6 concentrations relate to outcomes in burn-injured patients. $J$ Burn Care Rehabil. 2003;24:133-141.

21. Yeh FL, Lin WL, Shen HD, Fang RH. Changes in circulating levels of interleukin 6 in burned patients. Burns. 1999;25:131-136.

22. Yeh FL, Shen HD, Fang RH. Deficient transforming growth factor beta and interleukin-10 responses contribute to the septic death of burned patients. Burns. 2002;28:631-637.

23. Spies M, Chappell VL, Dasu MR, Herndon DN, Thompson JC, Wolf SE. Role of TNF-alpha in gut mucosal changes after severe burn. Am J Physiol Gastrointest Liver Physiol. 2002;283: G703-G708.

24. Yeh FL, Lin WL, Shen HD. Changes in circulating levels of an anti-inflammatory cytokine interleukin 10 in burned patients. Burns. 2000;26:454-459.

25. Gosain A, Gamelli RL. A primer in cytokines. J Burn Care Rehabil. 2005;26:7-12.

26. Madsen KL, Lewis SA, Tavernini MM, Hibbard J, Fedorak RN. Interleukin 10 prevents cytokine-induced disruption of T84 monolayer barrier integrity and limits chloride secretion. Gastroenterology. 1997;113:151-159.

27. Gardiner K, Barbul A. Intestinal amino acid absorption during sepsis. JPEN J Parenter Enteral Nutr. 1993;17:277-283.

28. Gardiner KR, Ahrendt GM, Gardiner RE, Barbul A. Failure of intestinal amino acid absorptive mechanisms in sepsis. J Am Coll Surg. 1995;181:431-436.

29. Gardiner KR, Gardiner RE, Barbul A. Reduced intestinal absorption of arginine during sepsis. Crit Care Med 1995;23:12271232.

30. Gardiner KR, Gardiner RE, Barbul A. Peritonitis impairs intestinal absorption of proline and leucine in the rat. Br J Surg. 1994;81: 361-364.

31. Sodeyama M, Gardiner KR, Regan MC, Kirk SJ, Efron G, Barbul A. Sepsis impairs gut amino acid absorption. Am J Surg. 1993;165: 150-154.

32. Pietsch JB, Leonard D, Neblett WW, Abumrad NN, Ghishan FK. Burn injury alters intestinal glutamine transport. J Surg Res. 1989;46:296-299.

33. Nielsen CU, Brodin B, Jørgensen FS, Frokjaer S, Steffansen B. Human peptide transporters: therapeutic applications. Expert Opin Ther Pat. 2002;12:1-23. 
34. Brodin B, Nielsen CU, Steffansen B, Frokjaer S. Transport of peptidomimetic drugs by the intestinal di/tri-peptide transporter, PepT1. Pharmacol Toxicol. 2002;90:285-296.

35. Herndon DN, Wilmore DW, Mason AD. Development and analysis of a small animal model simulating the human postburn hypermetabolic response. J Surg Res. 1978;25:394-403.

36. Amidon GL, Kou J, Elliott RL, Lightfoot EN. Analysis of models for determining intestinal wall permeabilities. J Pharm Sci. 1980;69:1369-1373.

37. Oh D-M, Sinko PJ, Amidon GL. Characterization of the oral absorption of several aminopenicillins: determination of intrinsic membrane absorption parameters in the rat intestine in situ. Int J Pharm. 1992;85:181-187.

38. Johnson DA, Amidon GL. Determination of intrinsic membrane transport parameters from perfused intestine experiments: a boundary layer approach to estimating the aqueous and unbiased membrane permeabilities. J Theor Biol. 1988;131:93-106.

39. Fagerholm U, Johansson M, Lennernas H. Comparison between permeability coefficients in rat and human jejunum. Pharm Res. 1996;13:1336-1342.

40. Chu XY, Sanchez-Castano GP, Higaki K, Oh DM, Hsu CP, Amidon GL. Correlation between epithelial cell permeability of cephalexin and expression of intestinal oligopeptide transporter. J Pharmacol Exp Ther. 2001;299:575-582.

41. Landowski CP, Sun D, Foster DR, et al. Gene expression in the human intestine and correlation with oral valacyclovir pharmacokinetic parameters. J Pharmacol Exp Ther. 2003;306:778-786.

42. Bahrami S, Schlag G, Yao YM, Redl H. Significance of translocation/ endotoxin in the development of systemic sepsis following trauma and/or haemorrhage. Prog Clin Biol Res. 1995;392:197-208.

43. Fink MP. Gastrointestinal mucosal injury in experimental models of shock, trauma, and sepsis. Crit Care Med. 1991;19:627-641.

44. Stojadinovic A, Smallridge R, Nath J, Ding X, Shea-Donohue T. Anti-inflammatory effects of $\mathrm{U} 74389 \mathrm{~F}$ in a rat model of intestinal ischemia/reperfusion injury. Crit Care Med. 1999;27:764-770.

45. Di Paolo MC, Merrett MN, Crotty B, Jewell DP. 5-Aminosalicylic acid inhibits the impaired epithelial barrier function induced by gamma interferon. Gut. 1996;38:115-119.

46. Chavez AM, Menconi MJ, Hodin RA, Fink MP. Cytokine-induced intestinal epithelial hyperpermeability: role of nitric oxide. Crit Care Med. 1999;27:2246-2251.

47. Unno N, Menconi MJ, Smith M, Fink MP. Nitric oxide mediates interferon-gamma-induced hyperpermeability in cultured human intestinal epithelial monolayers. Crit Care Med. 1995;23:11701176.

48. Molmenti EP, Ziambaras T, Perlmutter DH. Evidence for an acute phase response in human intestinal epithelial cells. J Biol Chem. 1993268:14116-14124.

49. Wang L, Walia B, Evans J, Gewirtz AT, Merlin D, Sitaraman SV. IL-6 induces NF- $\kappa \mathrm{B}$ activation in the intestinal epithelia. $J$ Immunol. 2003;171:3194-3201.

50. Hardin J, Kroeker K, Chung B, Gall DG. Effect of proinflammatory interleukins on jejunal nutrient transport. Gut. 2000;47:184-191.

51. Neudeck BL, Foster DR, Li Y, Gonzales JP, Welage LS. The effects of thermal injury on transcellular permeability and intestinal P-glycoprotein in rats. Burns. 2003;29:803-809.
52. Payne JW, Payne GM, Gupta S, Marshall NJ, Grail BM. Conformational limitations of glycylsarcosine as a prototypic substrate for peptide transporters. Biochim Biophys Acta. 2001;1514: 65-75.

53. Bertilsson PM, Olsson P, Magnusson KE. Cytokines influence mRNA expression of cytochrome P450 3A4 and MDRI in intestinal cells. J Pharm Sci. 2001;90:638-646.

54. Rodriguez P, Heyman M, Candalh C, Blaton MA, Bouchaud C. Tumour necrosis factor- $\alpha$ induces morphological and functional alterations of intestinal HT29 cl.19A cell monolayers. Cytokine. 1995;7:441-448.

55. Berg S, Sappington PL, Guzik LJ, Delude RL, Fink MP. Proinflammatory cytokines increase the rate of glycolysis and adenosine-5'-triphosphate turnover in cultured rat enterocytes. Crit Care Med. 2003;31:1203-1212.

56. Lu J, Philpott DJ, Saunders PR, Perdue MH, Yang PC, McKay DM. Epithelial ion transport and barrier abnormalities evoked by superantigen-activated immune cells are inhibited by interleukin-10 but not interleukin-4. J Pharmacol Exp Ther. 1998;287: 128-136.

57. Ogle CK, Mao JX, Hasselgren PO, Ogle JD, Alexander JW. Production of cytokines and prostaglandin E2 by subpopulations of guinea pig enterocytes: effect of endotoxin and thermal injury. $J$ Trauma. 1996;41:298-305.

58. Lundqvist C, Melgar S, Yeung MM, Hammarstrom S, Hammarstrom ML. Intraepithelial lymphocytes in human gut have lytic potential and a cytokine profile that suggest $\mathrm{T}$ helper 1 and cytotoxic functions. J Immunol. 1996;157:1926-1934.

59. Foster DR, Landowski CP, Amidon GL, Welage LS. Interferongamma increases expression of the di/tri-peptide transporter, h-PEPT1, and dipeptide transport in cultured human intestinal monolayers. Pharmacolog Res. 2009;59:215-220.

60. Tanaka H, Miyamoto KI, Morita K, et al. Regulation of the PepT1 peptide transporter in the rat small intestine in response to 5 -fluorouracil-induced injury. Gastroenterology. 1998;114:714-723.

61. Thamotharan M, Bawani SZ, Zhou X, Adibi SA. Functional and molecular expression of intestinal oligopeptide transporter (Pept-1) after a brief fast. Metabolism. 1999;48:681-684.

62. Ihara T, Tsujikawa T, Fujiyama Y, Bamba T. Regulation of PepT1 peptide transporter expression in the rat small intestine under malnourished conditions. Digestion. 2000;61:59-67.

63. Chen Z, Wang S, Yu B, Li A. A comparison study between early enteral nutrition and parenteral nutrition in severe burn patients. Burns. 2007;33:708-712.

64. Prelack K, Dylewski M, Sheridan RL. Practical guidelines for nutritional management of burn injury and recovery. Burns. 2007; 33:14-24.

65. Bai JP, Amidon GL. Structural specificity of mucosal-cell transport and metabolism of peptide drugs: implication for oral peptide drug delivery. Pharm Res. 1992;9:969-978.

66. Friedman DI, Amidon GL. Intestinal absorption mechanism of dipeptide angiotensin converting enzyme inhibitors of the lysylproline type: lisinopril and SQ 29,852. J Pharm Sci. 1989;78:995-998.

67. Foster DR, Zheng X. Cephalexin inhibits N-formylated peptide transport and intestinal hyperpermeability in Caco2 cells. J Pharm Pharm Sci. 2007;10:299-310. 